\title{
Analysis of a Methanol-Power Polygeneration System from Natural Gas
}

\author{
Xiaona Song \\ Electrical and Mechanical Practice Center, Beijing Information Science \& Technology University, Beijing, China \\ Email: songxiaona@bistu.edu.cn, xgncepu@163.com
}

Received November 2013

\begin{abstract}
This paper analyzes the characteristics of a Natural Gas (NG)-based Methanol-Power Polygeneration System (MPPS). The structures and parameters of the polygeneration systems are investigated to explore the appropriate process for each polygeneration system. And some effective methods, such as exergy distribution analysis and energy-utilization diagrams (EUD) are adopted to investigate the performance $\&$ characteristic of the system. The results reveal that, MPPS adopted Partial Reforming and Partial Cycling synthesis (PR/PC) process can reach good performance, while MPPS exhibits poor performance when adopting Full Reforming and Once Through synthesis (FR/OT) process. Through further study with exergy analysis method, we find that the particular synthesis and separation properties of methanol lead to such difference. Therefore, the characteristics of chemical product should be important factors in the configuration and integration of polygeneration systems. The work of this paper is significant for the research and development of polygeneration system.
\end{abstract}

\section{Keywords}

Polygeneration System; Exergy Distribution Analysis; EUD

\section{Introduction}

How to enhance the efficiency is an eternal topic for energy utilization system. To achieve this target, most efforts are focused on elevating the performance of components and system integration. For system integration, the idea of integrating of the chemical process and power production process, also known as polygeneration system, is rising and attracting more and more attentions [1-7].

Generally, most of studies on polygeneration system are focused on system innovation, performance study, exergy analysis, or techno-economic analysis. For example, Gao L. et al. analyzed coal-based polygeneration system by means of exergy method [2]. Li H., et al. proposed a new natural gas-based polygeneration system for power and methanol production [3]. Michiel J.A. et al. discussed the possibilities of biomass-based polygeneration system [4]. Chiesa P. et al. proposed a series of hydrogen-electricity polygeneration systems with $\mathrm{CO}_{2}$ capture and made comparative analysis of these systems [5]. Kreutz T. et al. made techno-economic analysis of these hydrogen-electricity polygeneration systems [6]. Jin H. et al. proposed a new kind of polygeneration system with multi fossil fuels and multi-products [7]. However, few studies paid attention to the impact on system characteristics brought by the internal property of chemical production process. However, such impact is an im- 
portant factor for design and optimization of polygeneration systems.

The aims of this paper are: 1 ) to study the characteristics of different NG-based polygeneration systems; 2) to discuss the impacts on system characteristics brought by different chemical products; 3 ) to explore the appropriate process and parameters for different polygeneration systems.

\section{Configuration of Natural Gas Based Polygeneration System}

Sequential process is a high performance structure of polygeneration system. As shown in Figure 1, sequential NG-based polygeneration system consists of reform, synthesis, separation, heat recovery and power generation units. In this kind of system, all of natural gas is fed into the reform unit, in which a certain amount of natural gas is converted to $\mathrm{CO}$ and $\mathrm{H}_{2}$ (syngas). After being cooled in heat recovery unit, syngas enters into the synthesis unit. By using different catalysts, various chemical products, such as methanol and DME, can be synthesized here. Then the raw product enters into separation unit, in which the chemical product will be separated out. The remaining, i.e. unreacted gas, can be sent to reform unit and power generation system as fuel, as well as be cycled back to the entrance of synthesis unit. The power generation unit, which is located after the separation unit, consumes a part of unreacted gas and provides the steam and work for other units or for outside.

The sequential polygeneration system is a general term of a group of systems which have the same feature of the sequential configuration of chemical process and power generation unit. Besides this common feature, different sequential polygeneration systems may be various in structure and parameters. Here are two different processes which all belong to the sequential NG-based polygeneration system.

1) Full Reforming and Once Through synthesis process (FR/OT). This kind of polygeneration process adopts the full reforming scheme and the once through synthesis scheme. That is, in reform unit, nearly all of the natural gas is converted to syngas. While in synthesis unit, the syngas will go through only once, all of the unreacted gas will be sent to reform unit and power generation unit as fuel, namely, the cycled gas will be canceled. This process can be shown in Figure 1 without the cycled gas.

2) Partial Reforming and Partial Cycling synthesis process (PR/PC). This kind of polygeneration process adopts the partial reforming scheme and the partial cycling synthesis scheme. That is, instead of being totally reformed, the natural gas entering into the reformer will be partially converted to syngas through lowering the reforming temperature and the ratio of steam to NG. Besides, only part of unreacted gas will be fed to reform unit and power generation unit as fuel, the remaining will be cycled. This process can be shown in Figure $\mathbf{1}$ with the cycled gas reserved.

\section{Analysis of NG-Based Methanol-Power Polygeneration System (MPPS)}

\subsection{Evaluation Criteria of Polygeneration System}

Energy Saving Ratio (ESR) is adopted to evaluate the performance of the polygeneration system, which is identified as follows:

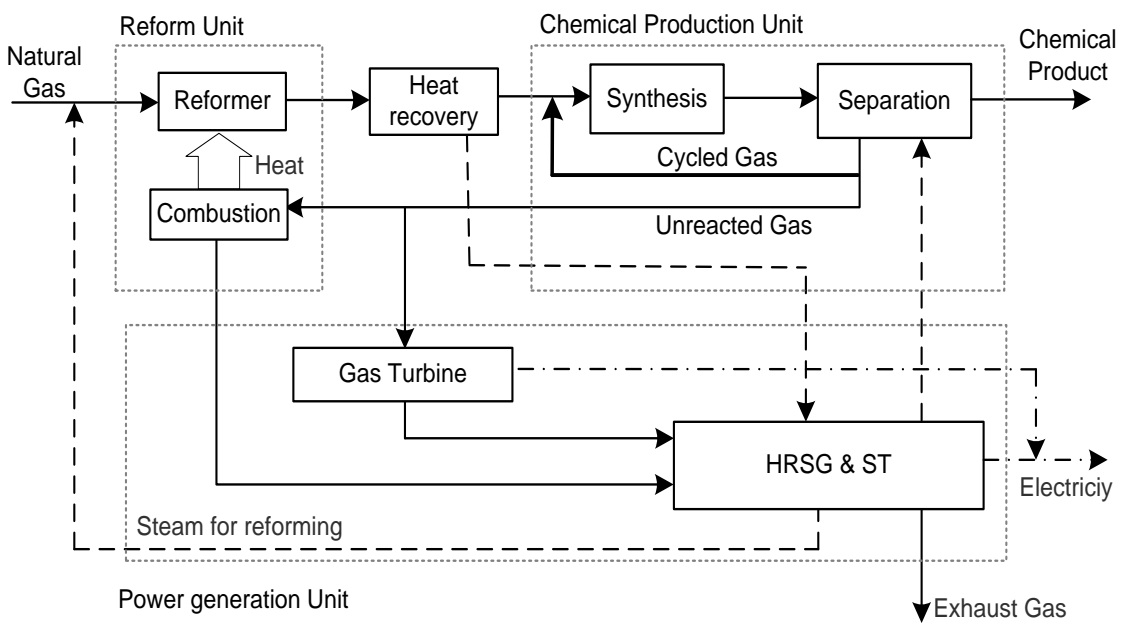

Figure 1. Flow diagram of sequential NG-based polygeneration. 


$$
E S R=\frac{(W / \eta+e \cdot M)-F}{W / \eta+e \cdot M}
$$

where $\boldsymbol{F}$ is the total fuel consumption of polygeneration system; $\boldsymbol{W}$ and $\boldsymbol{M}$ denote the work output and the mass of chemical product respectively; $\boldsymbol{\eta}$ is the thermal efficiency of individual power generation system; $\boldsymbol{e}$ is the energy consumption for per chemical product of individual chemical production process. Thus, ESR represents the energy saved of polygeneration system compared with the individual systems when they produce the same outputs.

\subsection{Performance Analysis of MPPS}

Methanol is an important product of natural gas, it is also a common chemical product of NG-based polygeneration system [2,3,8]. In this paper, the FR/OT and PR/PC processes of methanol-power polygeneration system (MPPS) are simulated and analyzed. The main parameters and performance indexes of the two processes are shown in Table 1. Exergy analysis results are shown in Table 2. For the two tables, the comparison is based on that the polygeneration system and the corresponding individual system have the same outputs.

We can see from Table 1 that the differences between two processes are significant. For example, the ESR of FR/OT process is only $0.03 \%$; while for PR/PC process, the ESR can reach $6.05 \%$. Exergy analysis results (Table 2) reveals that, compared with individual system, the performance improvement of PR/PC polygeneration

Table 1. Performance comparison of NG-based MPPS.

\begin{tabular}{|c|c|c|c|c|c|c|}
\hline & \multicolumn{2}{|c|}{ Individual systems } & \multirow{2}{*}{$\begin{array}{l}\text { FR/OT } \\
\text { Process }\end{array}$} & \multicolumn{2}{|c|}{ Individual systems } & \multirow{2}{*}{$\begin{array}{l}\mathrm{PR} / \mathrm{PC} \\
\text { process }\end{array}$} \\
\hline & chemical & power & & chemical & power & \\
\hline Fuel Energy Consumption (LHV, kW) & 193832.6 & 122394.9 & 316120.9 & 214450.1 & 122009.8 & 316120.9 \\
\hline Reforming ratio & $93.82 \%$ & & $93.82 \%$ & $93.82 \%$ & & $59.14 \%$ \\
\hline cycling ratio & 5.35 & & 0 & 5.35 & & 4.94 \\
\hline Conversion ratio of syngas to methanol & $96.07 \%$ & & $50.42 \%$ & $96.07 \%$ & & $89.75 \%$ \\
\hline Net work output $W(\mathrm{~kW})$ & & 68512.6 & 68512.6 & & 68297.1 & 68297.1 \\
\hline Methanol production $M(\mathrm{~kg} / \mathrm{hr})$ & 21577.3 & & 21577.3 & 23872.5 & & 23872.5 \\
\hline Thermal efficiency $\eta$ (LHV, \%) & & $55.98 \%$ & & & $55.98 \%$ & \\
\hline $\begin{array}{l}\text { Energy consumption for per chemical } \\
\text { product } e(\mathrm{LHV}, \mathrm{GJ} / \mathrm{t})\end{array}$ & 32.34 & & & 32.34 & & \\
\hline ESR (\%) & & & $0.03 \%$ & & & $6.05 \%$ \\
\hline
\end{tabular}

Table 2. Comparison of exergy distributions in NG-based MPPS (Unit: kW).

\begin{tabular}{|c|c|c|c|c|c|c|c|}
\hline & & $\begin{array}{l}\text { Individual } \\
\text { system }\end{array}$ & $\begin{array}{l}\text { MPPS with } \\
\text { FR/OT Process }\end{array}$ & Reduction & $\begin{array}{l}\text { Individual } \\
\text { system }\end{array}$ & $\begin{array}{c}\text { MPPS with } \\
\text { PR/PC Process }\end{array}$ & Reduction \\
\hline \multirow[t]{3}{*}{ Input } & Fuel & 330,231 & 330129 & & 351,501 & 330,129 & \\
\hline & Reforming unit & 29,811 & 49358 & 19,547 & 32,965 & 31,567 & 1398 \\
\hline & Synthesis unit & 9405 & 8237 & 1168 & 10,400 & 10,033 & 368 \\
\hline \multirow{4}{*}{$\begin{array}{l}\text { Exergy } \\
\text { losses }\end{array}$} & Separation unit & 4269 & 2771 & 1498 & 4721 & 3351 & 1370 \\
\hline & $\begin{array}{l}\text { Heat recovery \& } \\
\text { power generation }\end{array}$ & 84,255 & 67,273 & 16,983 & 86,824 & 68,685 & 18,139 \\
\hline & Total & 127,741 & 127,640 & 102 & 134,911 & 113,635 & 21,276 \\
\hline & Methanol output & 134,073 & 134,073 & & 148,257 & 148,257 & \\
\hline \multirow[t]{2}{*}{ output } & Power output & 68,453 & 68,453 & & 68,374 & 68,374 & \\
\hline & Sum of efflux & 330,267 & 330,166 & & 351,542 & 330,266 & \\
\hline
\end{tabular}


system due to the reduction of exergy loss of various units, especially the Heat recovery \& power generation unit. Such reduction of exergy loss actually comes from that polygeneration system can better utilize energy through integrating of the chemical process and power plant. For FR/OT process, though other units can also achieve the remarkable reduction of exergy loss, the exergy loss of reforming unit increases greatly than that of individual system, which consequently leading to low ESR.

\subsection{Graphical Exergy Analysis of Reforming Process}

To further study the reforming unit, a graphical exergy analysis methodology, which is called energy-utilization diagrams (EUD), is adopted. In EUD diagrams, abscissa $\Delta H$ represents the enthalpy transformation quantity. And the ordinate $A$ represents energy level. The area enclosed by energy discharging curve $A_{d}$ and receiving curve $A_{c}$ represents the quantity of exergy loss in the process. Thus, in a graphical way, we can reveal the essence of energy utilization in key process and provide reference for improvement $[9,10]$.

Figure 2 shows the EUD diagrams of reforming unit of MPPS, in which the dotted lines represent the EUD diagram of reforming unit of corresponding individual systems. For FR/OT process, we can see from Figure 2(a) that it is the increasement of $\Delta H$, which represents energy consumption of reforming reaction, that lead to great growth of exergy loss in reforming unit of polygeneration system. As the conversion ratio of syngas to methanol is very low in FR/OT process, to ensure same methanol output, polygeneration system need to generate more syngas than the corresponding individual system, which cause great increasement in energy consumption and exergy loss in reforming unit.

However, for PR/PC process, the higher conversion ratio of syngas to methanol makes the needed syngas decrease. Consequently, the energy consumption and exergy loss of reforming unit are reduced. Furthermore, the condition required by reforming reaction in this process is lowered, which reduces the energy consumption and exergy loss further.

Therefore, for MPPS, the main reason for the low ESR of FR/OT process is that the conversion ratio of syngas to methanol is too low (Table 1). And the low one-through conversion rate is the inherent characteristics of methanol synthesis. While for PR/PC process, because the condition of reforming reaction is lowered and the cycling ratio rises (Table 1), exergy loss of reforming unit are reduced greatly, and the conversion ratio of syngas to methanol can significantly increase (Table 2), which ensure the good performance of the PR/PC process.

\section{Conclusions}

This paper studies the characteristics of NG-based Methanol-Power Polygeneration System, and also explores the appropriate process and parameters for Methanol-Power polygeneration systems.

The results indicated that: 1) Different chemical products have distinct impact on performance of NG-based polygeneration system. 2) For Methanol-Power Polygeneration System (MPPS), the PR/PC process with high cycle ratio is more suitable. 3) The reason for above phenomenon lies in the internal property of methanol synthesis and separation process.

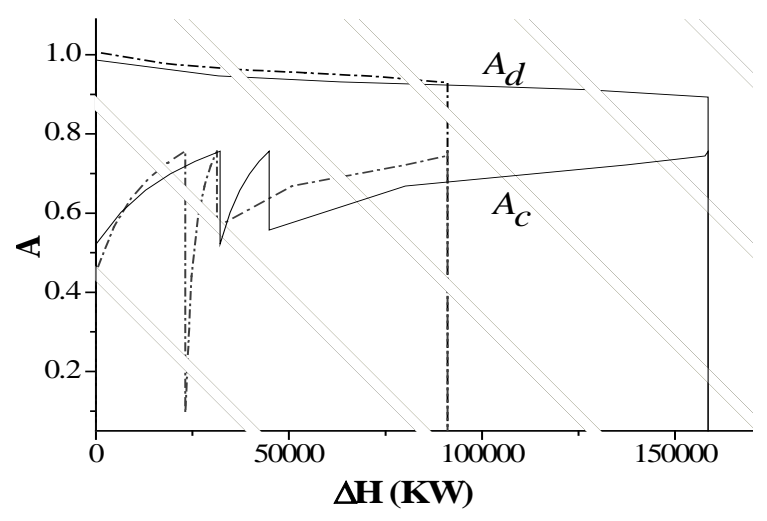

(a)

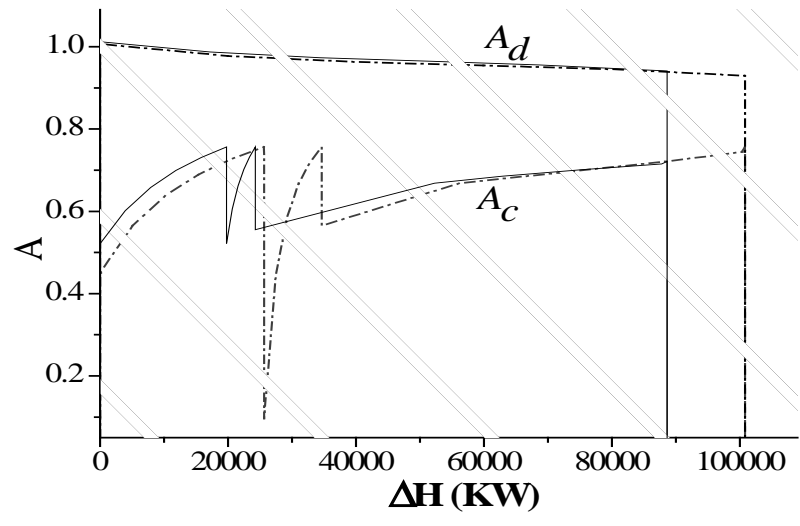

(b)

Figure 2. Energy-Utilization Diagram (EUD) of reforming unit of MPPS. (a) FR/OT process; (b) PR/PC process. 


\section{Acknowledgements}

This study has been supported by the Beijing College Youth Fellowship Program, 2013.

\section{References}

[1] Jackson, R.G. (1989) Polygeneration System for Power and Methanol Based on Coal Gasification. Coal Conversion, 3, 60-64.

[2] Gao, L., Jin, H., Liu, Z., et al. (2004) Exergy Analysis of Coal-Based Polygeneration System for Power and Chemical Production. Energy, 29, 2359-2371. http://dx.doi.org/10.1016/j.energy.2004.03.046

[3] Li, H., Gao, L., Chen, B., et al. (2006) Proposal of a Natural-Gas Based Polygeneration System for Power and Methanol Production. Proceedings of ECOS, Crete, 679-686.

[4] Michiel, J.A., Andre, P.C., Carlo, N., et al. (2002) Exploration of the Possibilities for Production of Fischer Tropsch Liquids and Power via Biomass Gasfication. Biomass \& Bioenergy, 23, 129-152. http://dx.doi.org/10.1016/S0961-9534(02)00037-5

[5] Chiesa, P., Consonni, S., Kreutz, T., et al. (2005) Co-Production of Hydrogen, Electricity, and $\mathrm{CO}_{2}$ from Coal with Commercially Ready Technology. Part A: Performance and Emissions. Hydrogen Energy, 30, 747-767. http://dx.doi.org/10.1016/j.ijhydene.2004.08.002

[6] Kreutz, T., Williams, R., Consonni, S. and Chiesa, P. (2005) Co-Production of Hydrogen, Electricity, and $\mathrm{CO}_{2}$ from Coal with Commercially Ready Technology. Part B: Economic Analysis. Hydrogen Energy, 30, 769-784. http://dx.doi.org/10.1016/j.jjhydene.2004.08.001

[7] Jin, H., Han, W. and Gao, L. (2007) Multi-Functional Energy System (MES) with Multi Fossil Fuels and Multi Products. Journal of Engineering for Gas Turbines and Power, 129, 331-337. http://dx.doi.org/10.1115/1.2432895

[8] Steinberg, M. (1998) Production of Hydrogen and Methanol from Natural Gas with Reduced $\mathrm{CO}_{2}$ Emission. International Journal of Hydrogen Energy, 23, 419-425. http://dx.doi.org/10.1016/S0360-3199(97)00092-X

[9] Jin, H., Ishida, M., Kobayashi, M., et al. (1997) Energy Evaluation of Two Current Advanced Power Plants: Supercritical Steam Turbine and Combined Cycle. Journal of Energy Resources Technology, 119, 250-256. http://dx.doi.org/10.1115/1.2794998

[10] Jin, H. and Ishida, M. (1993) Graphical Energy Analysis of Complex Cycles. Energy, 18, 615-625. http://dx.doi.org/10.1016/0360-5442(93)90040-K 